\title{
Heliconema anguillae Yamaguti, 1935, a physalopterid nematode found in Japanese eels: taxonomic resurrection with a note on the third-stage larva from intertidal crabs in western Japan
}

\author{
Hirotaka Katahira ${ }^{1}$ and Kazuya Nagasawa ${ }^{2}$ \\ ${ }^{1}$ Graduate School of Environmental Earth Science, Hokkaido University, Sapporo, Hokkaido, Japan; \\ ${ }^{2}$ Graduate School of Biosphere Science, Hiroshima University, Hiroshima, Japan
}

\begin{abstract}
A parasitic nematode from the stomach of Japanese eel Anguilla japonica Temminck et Schlegel in western Japan, previously identified as Heliconema longissimum (Ortlepp, 1922), was morphologically re-examined and compared with the previous descriptions. In addition, the third-stage larva of this nematode is described, based on the specimens of encapsuled larvae found in musculature of two crabs, Hemigrapsus sp. and Perisesarma bidens (De Haan), caught from the upper-intertidal zone of the same locality. As a result of the morphological observation, seven pairs of postcloacal papillae in adult males are confirmed. This matches with the character of H. longissimum, but the shape of the fifth postcloacal papillae differs between the present material and H. longissimum; the former possesses pedunculate papillae in the fifth pair whereas the latter has sessile papillae. Since the pedunculate papillae can be found in the original description and the syntype specimens of $H$. anguillae Yamaguti, 1935 that has been synonymised with $H$. longissimum, we thus here resurrect $H$. anguillae as an accepted species. For the life-cycle of the present nematode, littoral crabs, including the two infected species, are likely to be the source of infections for Japanese eels, acting as intermediate hosts.
\end{abstract}

Keywords: Nematoda, parasitic nematode, taxonomy, morphology, intermediate hosts, littoral crabs

The genus Heliconema Travassos, 1919 (Physalopteridae) is a group of parasitic nematodes characterised by two lateral pseudolabia and specific cephalic dentation on the internal border of each pseudolabium with a lateral marked-tooth and two dorsoventral simple-teeth (Moravec 2007, Moravec et al. 2007, Chabaud 2009). This nematode group is primarily found in anguilliform fishes (Anderson 2000) and presently consists of 14 species (see Crites and Overstreet 1991, Moravec 1998, Moravec et al. 2007, 2008, 2013a, b): 12 valid species, namely $H$. africanum (Linstow, 1899), H. heliconema Travassos, 1919 (typespecies), H. longissimum (Ortlepp, 1922), H. brevispiculum Baylis, 1934, H. ahiri Karve, 1941, H. baylisi Ogden, 1969, H. serpens Fusco et Palmieri, 1980, H. psammobatidus Threlfall et Carvajal, 1984, H. kherai Gupta et Duggal, 1989, H. brooksi Crites et Overstreet, 1991, and H. savala Akram, 1996; H. hainanensis Li, Liu, Liu et Zhang, 2013, and two species inquirendae, H. urolophi (Johnston et Mawson, 1951) and H. hamiltonii Bilqees et Khanum, 1970.

In recent years, taxonomic reviews have been conducted on the genus Heliconema, which has improved our understandings on the classification of this group. Moravec et al. (2007) provided useful taxonomic criterion to discriminate this genus from the other related genera belonging to the subfamily Proleptinae, in addition to the redescription of $H$. longissimum based on the specimens from rice-paddy eels Pisodonophis boro (Hamilton) in brackish waters of Thailand. Li et al. (2013) subsequently discovered an undescribed species from congers Uroconger lepturus (Richardson) (type host), Muraenesox cinereus (Forsskål) and Congresox talabonoides (Bleeker) in the South China Sea, which was described as H. hainanensis. Meanwhile, Moravec et al. (2013b) have recognised that a species, previously thought as $H$. longissimum (see Taraschewski et al. 2005), from African longfin eels Anguilla mossambica (Peters) in freshwater habitats of South Africa can be identical with $H$. africanum. Moravec et al. (2013a) furthermore re-examined taxonomic status of $H$. ahiri, previously considered as a junior synonym as H. longissimum, and resurrected it based on the material from Indonesian shortfin eels Anguilla bicolor bicolor McClelland of southern India.

Due to the sequence of awareness on the previous confusions, careful identifications are presently required for the obtained specimens of the genus Heliconema. In particular, Moravec et al. (2013b) doubted taxonomic status of H. longissimum and suggested a possibility of its com-

Address for correspondence: H. Katahira, Graduate School of Environmental Earth Science, Hokkaido University, N10W5, Sapporo, Hokkaido 060-0810, Japan. Phone: +81-11-706-2245; Fax: +81-11-706-4864; E-mail: paraparaparasites@gmail.com 
plexity consisting of several morphologically closely related species. Under this situation, it is questionable that $H$. longissimum has so far been reported not only from saline environments in Japan and Thailand (Moravec et al. 2007, Katahira et al. 2011) but also from fresh waters in other regions (Ogden 1969, Sood 1970, De et al. 1978, De 1988; see also Moravec et al. 2007). It thus appears that the specimens, previously identified as $H$. longissimum, need to be morphologically re-examined to confirm their validity.

In Japanese waters, H. longissimum is known as a stomach parasite of Japanese eels Anguilla japonica Temminck et Schlegel (see Nagasawa et al. 2007). Although Yamaguti (1935) originally described H. anguillae Yamaguti, 1935 from Japanese eels without stating its sampling locality, this nematode was synonymised with $H$. longissimum by Ogden (1969). Since the first attempt of Yamaguti (1935), morphological investigation has never been conducted on the Japanese material of $H$. longissimum. In this paper, we re-examine the morphology of Japanese $H$. longissimum, based on the specimens collected by Katahira et al. (2011) from Japanese eels in a brackish-water cove of western Japan. We also describe the third-stage larva of the genus Heliconema found during a survey of decapods sympatrically occurring with Japanese eels.

\section{MATERIALS AND METHODS}

Two Japanese eels Anguilla japonica were caught with covert traps in the innermost part of Misho Cove $\left(32^{\circ} 57^{\prime} 30^{\prime \prime N}\right.$; $132^{\circ} 33^{\prime} 58^{\prime \prime E}$ ) in Ehime Prefecture, western Japan, on 31 August 2008 and 18 October 2008 (see Katahira et al. 2011). These eels were kept alive in oxygenated containers with ambient waters and brought to the laboratory of the Hiroshima University, where they were measured for total length (TL) in millimetres and examined for nematodes under a stereomicroscope. All nematode specimens were washed in physical saline, fixed in hot $70 \%$ ethanol and subsequently preserved in $70 \%$ ethanol.

Sampling of decapod crustaceans for larval nematodes was conducted in the intertidal flat of the innermost part of Misho Cove $\left(32^{\circ} 57^{\prime} 35^{\prime \prime} \mathrm{N} ; 132^{\circ} 33^{\prime} 05^{\prime \prime} \mathrm{E}\right)$ and two adjacent rivers, the Renjoji River $\left(32^{\circ} 57^{\prime} 27^{\prime \prime N}\right.$; $\left.132^{\circ} 34^{\prime} 05^{\prime \prime} \mathrm{E}\right)$ and the Sozu River $\left(32^{\circ} 57^{\prime} 44^{\prime \prime N}\right.$; $\left.132^{\circ} 33^{\prime} 30^{\prime \prime} \mathrm{E}\right)$, flowing into the cove; details of these localities have been described elsewhere (see Mizuno and Nagasawa 2010, Katahira et al. 2011). Decapods were caught by hands or hand nets in Misho Cove during low tides on 11 November 2013 and in the rivers on 10 November 2013. These decapods were kept alive in containers and brought to the laboratory of the Hiroshima University, where they were measured for carapace width $(\mathrm{CW})$ or total length (TL) in millimetres, and immediately examined for nematode larvae under a stereomicroscope. A total of 82 decapod specimens (nine families, 11 genera, 13 species) were collected, consisting of one unidentified species of penaeid shrimp (n $=1 ; 50 \mathrm{~mm}$ TL); two species of palaemonid shrimps, Palaemon pacificus (Stimpson) $(\mathrm{n}=6 ; 29-42$ [34.8] mm TL) and Palaemon serrifer (Stimpson) $(\mathrm{n}=1 ; 25 \mathrm{~mm} \mathrm{CW})$; one unidentified species of alphenid shrimp, Alpheus sp. ( $\mathrm{n}=1 ; 35 \mathrm{~mm}$ $\mathrm{TL}$ ); one species of upogebiid mud shrimp, Upogebia yokoyai Makarov ( $\mathrm{n}=1 ; 30 \mathrm{~mm} \mathrm{TL}$ ); one species of pagurid hermit crab, Pagurus minutus Hess $(\mathrm{n}=3$; measurements unavailable); one species of pilumnid rock crab, Pilumnopeus makianus (Rathbun) ( $\mathrm{n}=2 ; 12-15 \mathrm{~mm} \mathrm{CW})$; three species of varunid crabs, Hemigrapsus sanguineus (De Haan) $(\mathrm{n}=13 ; 6-14$ [average 10] $\mathrm{mm}$ $\mathrm{CW})$, Hemigrapsus sp. $(\mathrm{n}=39 ; 7-21[12] \mathrm{mm} \mathrm{CW})$ and Helice tridens (De Haan) $(\mathrm{n}=4 ; 17-25$ [21] mm CW); two species of sesarmid crabs, Sesarma dehaani H. Milne Edwards ( $\mathrm{n}=2$; 25-30 mm CW) and Perisesarma bidens (De Haan) $(\mathrm{n}=8 ; 8-18$ [15] $\mathrm{mm} \mathrm{CW}$ ); and one species of macrophthalmid crabs, Macrophthalmus (Macrophthalmus) abbreviatus Manning et Holthuis ( $\mathrm{n}=1 ; 17 \mathrm{~mm} \mathrm{CW}$ ). In addition, 13 decapod specimens were caught from freshwater environments in the Renjoji River and the Sozu River: they were one species of palaemonid shrimp, Macrobrachium nipponense (De Haan) ( $\mathrm{n}=12 ; 63-90$ [78] mm TL); and one species of varunid crab, Eriocheir japonica (De Haan) $(\mathrm{n}=1 ; 39 \mathrm{~mm} \mathrm{CW})$. Like the adult specimens from Japanese eels, the larval nematodes recovered were washed in physical saline, fixed in hot $70 \%$ ethanol and stored in $70 \%$ ethanol.

For a microscopic examination, the nematode specimens were placed on glass slides and cleared with $35 \%$ glycerol; fully mature males and gravid females were randomly chosen from the specimens from Japanese eels. The specimens were examined under an Olympus BX51 light microscope using phase contrast optics. Drawings were made with the aid of a drawing tube and measurements were taken using an ocular micrometre; all measurements are given in micrometres $(\mu \mathrm{m})$ unless otherwise indicated and provided as the range followed by the mean in parentheses. For scanning electron microscopy (SEM), three male specimens from a Japanese eel caught on 18 October 2008 were dehydrated in an ethanol series, dried by hexamethyldisilazane, sputter-coated with gold and observed at $15 \mathrm{kV}$ accelerating voltage with a Hitachi S-3000N instrument. In addition to the above procedure, the syntype specimens of $H$. anguillae deposited in the Meguro Parasitological Museum, Tokyo (MPM Coll. No. 23939-23940) were examined because they were recently rediscovered in a preserved status of being flattened on glass slides. However, due to the poor condition (filled with mostly dried lactophenol), only limited body structures were measured. The common and scientific names of the decapods used in this paper follow WoRMS (2013).

\section{RESULTS}

Of the two Japanese eels examined, the smaller one (386 mm TL, 31 August 2008) was infected with 151 worms, whereas the larger one $(415 \mathrm{~mm}$ TL, 18 October 2008) harboured 389 worms.

Two species, i.e. Hemigrapsus sp. and Perisesarma bidens, were found infected with nematode larvae; two of 39 Hemigrapsus sp. and one of eight $P$. bidens were infected with the intensity of one worm in each individual. Infection site is the musculature at the mouthpart and the basal part of legs, where the larvae were encapsulated among muscle fibres.

The syntype specimens of Heliconema anguillae contained eight individuals (two males and two females collected on 27 January 1927, and one male and three females collected on 5 February 1927). The measurements of these specimens are presented in Table 1. The specimen illustrated by Yamaguti (1935) was not found in the museum collection. 
Table 1. Measurements (range with mean in parentheses; in micrometres unless otherwise stated) of the syntype specimens of Heliconema anguillae Yamaguti, 1935 from Anguilla japonica deposited in the Meguro Parasitological Museum, Tokyo.

\begin{tabular}{lcc}
\hline & Male $(\mathrm{n}=3)$ & Female $(\mathrm{n}=5)$ \\
\hline Total length (mm) & $1.71-2.69(2.30)$ & $2.00-3.47(2.92)$ \\
Maximum width & $360-552(463)$ & $447-662(567)$ \\
Oesophagus (mm) & $3.28-3.57(3.43)$ & $3.06-4.22(3.61)$ \\
Muscular portion & $418-446(432)$ & $436-591(502)$ \\
Glandular portion (mm) & $2.87-3.12(2.99)$ & $2.61-3.68(3.10)$ \\
Length ratio of glandular to muscular oesophagus & $6.86-7.00(6.93)$ & $5.50-6.77(6.19)$ \\
Nerve-ring position & $235-251(243)$ & $215-317(269)$ \\
Right spicule & $265-291(280)$ & - \\
Left spicule & $596-694(651)$ & - \\
Length ratio of left to right spicule & $2.25-2.38(2.32)$ & - \\
Egg & - & $42-48(44) \times 26-31(28)$ \\
Embryo & - & $34-40(37) \times 8-24(21)$ \\
Tail & - & $116-155(135)$ \\
\hline
\end{tabular}

Morphological details of the adult and larval worms recovered are given below.

Family Physalopteridae Railliet, 1893

Heliconema anguillae Yamaguti, 1935

Figs. 1A-I, 2A-F

Redescription: Body whitish, elongate, with transversely striated cuticle. Cephalic end rounded; cuticle in cephalic region thick, forming collar. Oral aperture dorsoventrally elongate, surrounded by 2 lateral pseudolabia. Pseudolabium roundish, bearing dorso- and ventrolateral cephalic papillae and lateroapical depression; lateral amphid situated at base of pseudolabium. Inner surface of pseudolabium with 1 trianglar terminal lateral tooth and 2 flat dorsoventral teeth. Buccal cavity short. Oesophagus divided into short muscular and long glandular portions. Nerve ring encircles muscular oesophagus at middle. Deirids small, situated at level of nerve ring. Excretory pore usually opening at anterior end of muscular oesophagus. Tail tip smooth, with no modification.

Male (based on 10 mature specimens): Body 16.4-23.2 (20.0) mm long, with 260-440 (336) in maximum width. Oesophagus 2.75-3.21 (3.01) mm long; muscular and glandular portions 370-455 (409) and 2.38-2.79 (2.60) $\mathrm{mm}$ long, respectively; length ratio of glandular to muscular oesophagus 1 : 5.7-7.2 (1: 6.4). Nerve ring, deirids and excretory pore situated at 240-270 (254), 240-320 (268) and 365-470 (417) from anterior extremity, respectively. Caudal end spirally coiled, provided with broad lateral alae supported by 4 pairs of precloacal and 7 pairs of postcloacal papillae; precloacal papillae pedunculate, situated subventrally and arranged in couples; first 4 postcloacal subventral pairs of papillae pedunculate; fifth postcloacal pair also situated subventrally and pedunculate but shorter and more slender than anterior 4; last pair sessile, situated ventrally; additional pair of sessile papillae situated ventrally at posterior to cloaca, poorly-developed and indistinct in most cases. Phasmids situated posterior to last pair of postcloacal papillae. Cloacal lip swollen high. Ventral precloacal surface with 13-14 longitudinal ridges. Spicules unequal and dissimilar; right spicule 215-275 (253) long; left spicule 538-731 (635) long; length ratio of left to right spicule 1 : 2.19-2.77 (1:2.51). Tail 263-383 (329) long.

Female (based on 10 gravid specimens): Body 20.1-28.9 (24.3) mm long, with 375-595 (452) in maximum width. Oesophagus 3.03-3.68 (3.34) mm long; muscular and glandular portions 415-535 (455) and 2.59-3.14 (2.88) $\mathrm{mm}$ long, respectively; length ratio of glandular to muscular oesophagus $1: 5.87-7.08(1: 6.35)$. Nerve ring, deirids and excretory pore situated at 215-285 (259), 235-325 (279) and 370-485 (418) from anterior extremity, respectively. Uterus situated at middle of body; vagina opening 10.5-15.8 (12.0) mm from anterior extremity, at about 45-55\% (49\%) of body. Eggs 41-46 (45) $\times 26-29$ (28), with embryo 33-38 (36) × 18-22 (20). Tail 125-168 (146) long.

Host: Japanese eel Anguilla japonica Temminck et Schlegel (Anguilliformes: Anguillidae).

L o cality: The innermost part of Misho Cove in Ehime Prefecture, western Japan (31 August 2008 and 18 October 2008).

Voucher specimens: 20 specimens deposited in vials with $70 \%$ ethanol in the National Museum of Nature and Science, Tsukuba, Ibaraki Prefecture, Japan (Coll. No. NSMTAs 4043) and the Helminthological collection of the Institute of Parasitology, Biology Centre of the Academy of Sciences of the Czech Republic, České Budějovice, Czech Republic (N-1091).

\section{Third-stage larvae of Heliconema anguillae}

Fig. 3A-K

Description (based on 1 female larva from Perisesarma bidens and 2 female larvae from Hemigrapsus sp.; no morphological or size difference between larvae from these crabs were observed): Body whitish, 6.9-14.3 mm $\times$ 140-300, with transversely striated cuticle. Cephalic end rounded; cuticle in cephalic region thick, forming collar, gradually thinner posteriorly to level of deirids, with 91-101 in maximum width $(n=2)$. Oral aperture dorsoventrally elongate, surrounded by 2 lateral pseudolabia. Pseudolabium roundish, bearing dorso- and ventrolateral cephalic papillae and lateroapical depression; lateral am- 

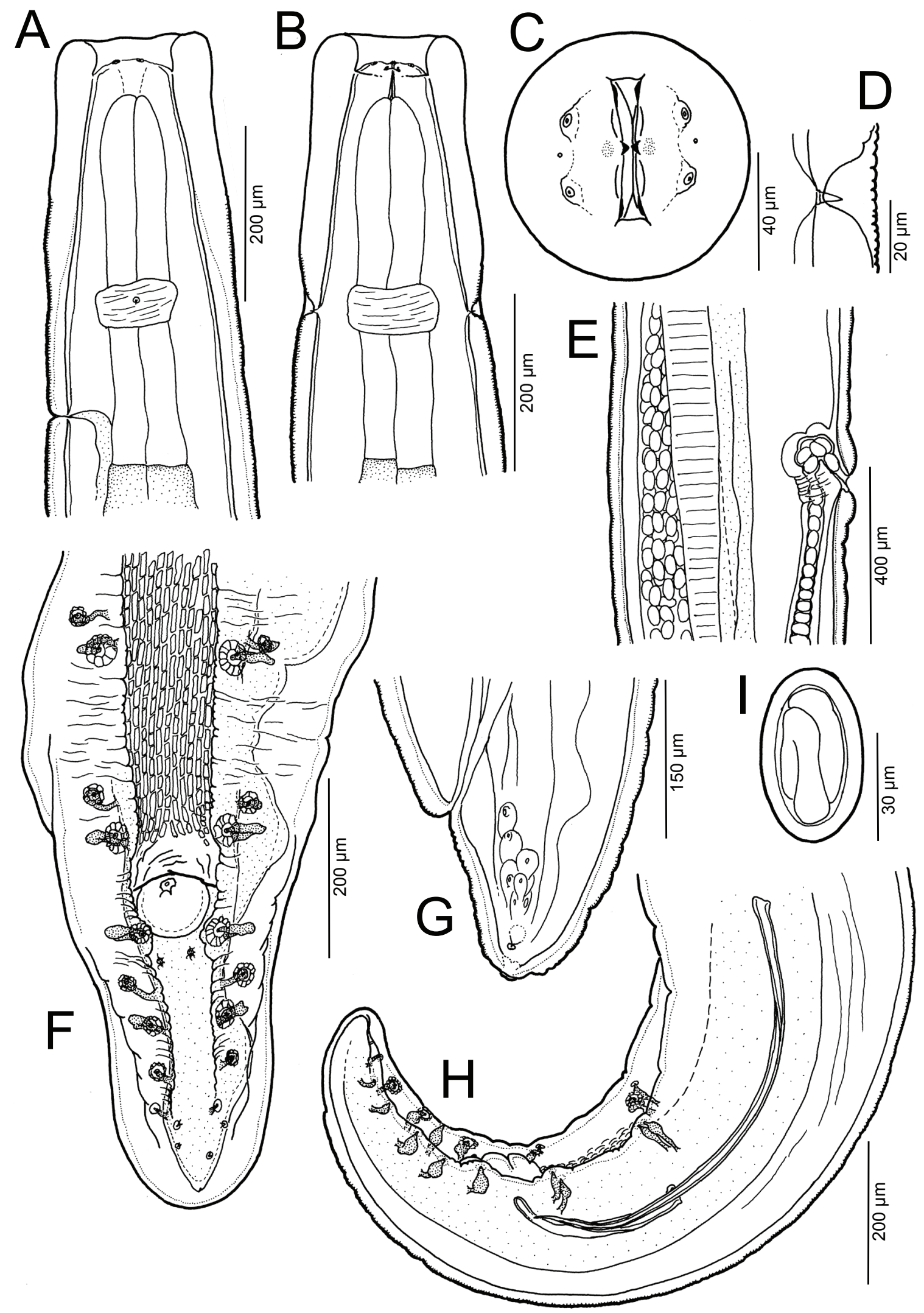

Fig. 1. Adult male and female of Heliconema anguillae Yamaguti, 1935 from Anguilla japonica. A - anterior end of body of male, lateral view; $\mathbf{B}$ - anterior end of body of the same male, dorsoventral view; $\mathbf{C}$ - cephalic end of the same male, apical view; $\mathbf{D}$ - deirid of the same male, magnified view; $\mathbf{E}$ - region of vulva of female; $\mathbf{F}$ - ventral view of caudal end of male; $\mathbf{G}$ - caudal end of female shown in E; $\mathbf{H}$ - caudal end of male shown in A, lateral view; $\mathbf{I}$ - egg of female shown in E. 


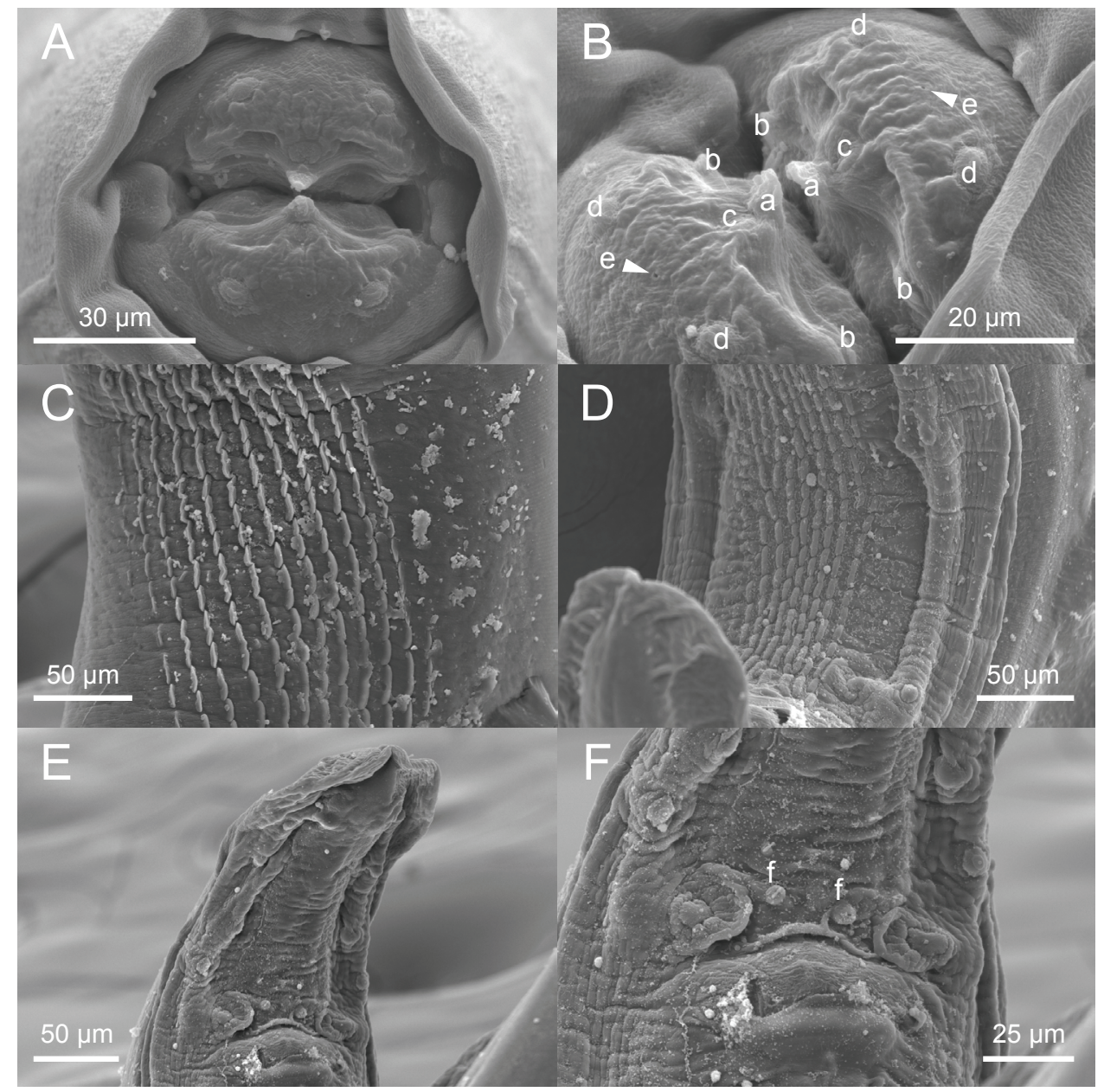

Fig. 2. Adult male of Heliconema anguillae Yamaguti, 1935 from Anguilla japonica. SEM micrographs. A - cephalic end, apical view; B - cephalic end, sublateral view; C - cuticular ridge, enlarged view; D - precloacal region; E - tail, ventral view; $\mathbf{F}$ - postcloacal region, enlarged view. Abbreviations: a - lateral teeth; b - dorsoventral teeth; c - lateroapical depression; d - cephalic papilla; e - amphid; $\mathrm{f}$ - additional pair of sessile papillae.

phid situated at base of pseudolabium. Inner surface of pseudolabium with 1 trianglar terminal lateral tooth and 2 flat dorsoventral teeth. Buccal cavity short. Oesophagus 1.91-2.28 mm long $(\mathrm{n}=2)$, divided into muscular and glandular portions, 262-343 long $(\mathrm{n}=2)$ and $1.63-2.16 \mathrm{~mm}$ long, respectively; length ratio of glandular to muscular oesophagus $1: 5.6-6.2$. Nerve ring at middle of muscular oesophagus. Deirids small, situated at nerve ring. Excretory pore opening at posterior of nerve ring. Nerve ring, deirids and excretory pore situated at 162-201 $(\mathrm{n}=2), 140-165$ $(\mathrm{n}=2)$ and $182-280(\mathrm{n}=2)$ from anterior extremity, respectively. Female genital primordium situated at middle of body; undeveloped vagina opening 2.9-4.4 mm $(\mathrm{n}=2)$ from anterior extremity, at about $42 \%$ of body. Tail $88-103$ long, with digitate tip.

Hosts: Hemigrapsus sp. (Decapoda: Varunidae) and Perisesarma bidens (De Haan) (Decapoda: Sesarmidae).

Locality: Upper-intertidal zone of the innermost part of Misho Cove in Ehime Prefecture, western Japan (11 November 2013).

Voucher specimens: 3 specimens deposited as vials with $70 \%$ ethanol in the National Museum of Nature and Science, Tsukuba, Ibaraki Prefecture, Japan (Coll. No. NSMT-As 4044).

\section{DISCUSSION}

The nematode examined in this study, previously reported as Heliconema longissimum from the same locality, is thought to be of marine origin because of halophilic distribution confirmed by the previous work (Katahira et al. 2011), with $100 \%$ or almost $100 \%$ prevalence and intensities of more than 80 worms per host. Originally, H. longissimum was described from an unidentified Australian snake (Ortlepp 1922), but later the identification of the type host was considered as doubtful (Chabaud and CampanaReuget 1956). Moravec et al. (2013b) also stated that a sea snake can be a postcyclic host via feeding on definitive fish hosts. In addition to this host complexity, they suspect that the name of $H$. longissimum may be a junior synonym of Heliconema africanum, because both species are morphologically very similar and the latter name is older than the former one (Moravec et al. 2013b). However, the specimens previously identified as $H$. longissimum from rice-paddy eels Pisodonophis boro in Thailand (Moravec et al. 2007) can be discriminated from $H$. africanum in having the larger number of postcloacal papillae in males (i.e. seven pairs $v s$ six pairs). Thus, unless the type material of $H$. longissimum is re-examined, it is now difficult to solve 

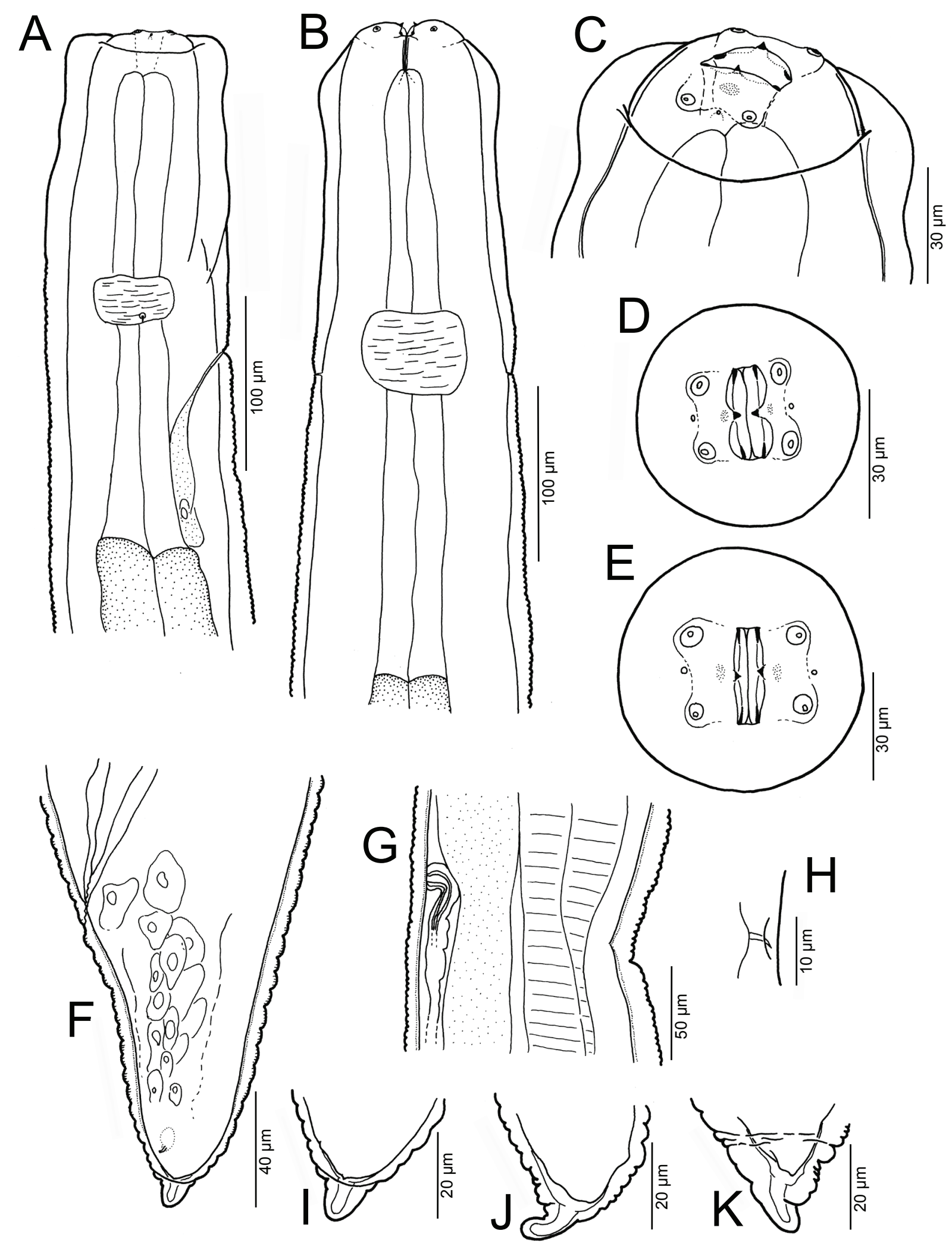

Fig. 3. Third-stage larvae of Heliconema anguillae Yamaguti, 1935 from littoral crabs. A - anterior end of body of larva from Hemigrapsus sp., lateral view; B - anterior end of body of larva from another Hemigrapsus sp., dorsoventral view; $\mathbf{C}$ - cephalic end of larva from Perisesarma bidens, sublateral view; D-E - cephalic end of larvae shown in A and B, respectively, apical view; $\mathbf{F}$ - caudal end of larva shown in A, magnified view; $\mathbf{G}$ - region of vulva of larva shown in A; H - deirid of larva shown in B; I-K - tail tip of larvae shown in $\mathrm{A}, \mathrm{B}$, and $\mathrm{C}$, respectively. 
the tangled problems, including our question whether the specimens from the saline environments and those from fresh waters are conspecific. However, due to the poor condition in the type material (see Ogden 1969), further taxonomic re-examinations are required based on new topotypic materials (Moravec et al. 2013b).

The taxonomic problems related to $H$. longissimum are due to difficulty of counting the number of papillae on the posterior end in males; in particular, the last two pairs of papillae and a pair of phasmids are sometimes hard to observe (Moravec et al. 2007). Ogden (1969) re-examined the paratypes of $H$. longissimum and the specimens from zig-zag eels Mastacembelus armatus (Lacepède) from Khagra in India and described four pairs of precloacal and five pairs of postcloacal papillae and a pair of phasmids. However, it can be thought that the pair of phasmids described in his paper may correspond to the sixth pair of postcloacal-subventral papillae (see Moravec et al. 2007), because De et al. (1978) reported six pairs of postcloacalsubventral papillae and a pair of phasmids based on the specimens recovered from the same host species $M$. armatus in a different locality of India. In another work by Sood (1970) based on the specimens from the same host species in the same country, additional small sessile papillae situated posterior to the cloaca were found, whereas the last two pairs of papillae were undescribed; Sood (1970) reported these specimens as Paraleptus komiyai Sood, 1970 that was subsequently synonymised as $H$. longissimum by De et al. (1978) and De (1988). Eventually, Moravec et al. (2007) concluded that the male of this nematode has seven pairs of postcloacal papillae.

In Japan, Yamaguti (1935) originally described Heliconema anguillae, which was regarded as a junior synonym of H. longissimum by Ogden (1969). In his description, Yamaguti (1935) reported the presence of four pairs of precloacal and five pairs of postcloacal pedunculate papillae in male specimens of $H$. anguillae collected from Japanese eels. He, however, may have overlooked the tiny structures, i.e. the last pair of papillae, an additional pair of papillae situated posterior to the cloaca, and a pair of phasmids, because these characters can be found in male specimens presently recovered from the same host species. These tiny structures are hard to observe in the syntype specimens of $H$. anguillae due to the poor preserved condition. The postcloacal papillae of Japanese specimens thus appear to be same as that of $H$. longissimum in number, but, in comparison with the description of $H$. longissimum by Moravec et al. (2007), the male specimens of our study and Yamaguti (1935) differ from those of the species in the morphology of the fifth pair of postcloacal papillae and the additional pair of papillae situated posterior to the cloaca. The fifth postcloacal papillae of Japanese specimens have a rather substantial and pedunculate shape and only the last pair of papillae is small and sessile. The additional pair of papillae is also sessile and indistinct in most of our specimens. Moreover, the size of embryonated eggs slightly differ between Japanese specimens (41-46 × 26-29 $\mu \mathrm{m}$ in the present study) and the description of $H$. longissimum (approximately $60 \times 30 \mu \mathrm{m}$ ) in Moravec et al. (2007).
Moravec et al. (2007) described the egg to be 75-81 $\mu \mathrm{m}$ long $\times 42-48 \mu \mathrm{m}$ wide in the text, but these measurements do not match the size of the illustrated egg. Although the range of other measurements, such as the length ratio of spicules (1 : 2.77-2.93), in our specimens overlaps with those in the previous descriptions of $H$. longissimum, including that of Moravec et al. (2007), we here resurrect $H$. anguillae as an accepted species that can be morphologically discriminated from $H$. longissimum.

The cephalic morphology of larval nematode specimens collected in this study is characterised by having two lateral pseudolabia bearing a triangular terminal and two flat dorsoventral teeth, which is the generic character of Heliconema (see Moravec 2007, Moravec et al. 2007, Chabaud 2009). The members of this genus are usually discriminated from each other based on the adult worm specimens, especially by using the genital features of males (i.e. the spicule ratio and the number of caudal papillae), as mentioned above. The larval observation thus has a limitation to precisely identify the species, but acceptable facts are available that no congener has ever been found from Japanese waters except for $H$. anguillae (see Nagasawa et al. 2007) and that this nematode species is commonly infecting Japanese eels in the study area (Katahira et al. 2011; the present study). This suggests that our larval nematode specimens belong to $H$. anguillae as found in Japanese eels, although further verifications, such as experimental infections or genetic analyses, are needed.

In the members of the genus Heliconema, utilisation of intermediate hosts is poorly understood because of little progress of field and experimental surveys. According to Crites and Overstreet (1991), a congeneric larva in the Mississippi Sound, supposed to belong to H. brooksi, uses the white shrimp Litopenaeus (= Penaeus) setiferus (Linnaeus) as an intermediate host. In addition, decapod crustaceans are generally an obligate source of infections for species of the nematode family Physalopteridae involving the genus Heliconema (see Anderson 2000, Moravec 2007, 2013). Moravec and Amin (1978) also reported that thirdstage larvae, probably belonging to Heliconema, occur in the abdominal cavity of a cyprinid fish, but the host is thought as a postintermediate host of the larvae (Moravec 2013). The present study first reports that $H$. anguillae may use littoral crabs as intermediate hosts, whereas the other congener (i.e. H. brooksi) is known to probably exploit shrimps (see Crites and Overstreet 1991). In other locality in Japan where an unidentified species of Heliconema was found (Suyehiro 1957), however, Japanese eels primarily feed on mud shrimps Upogebia major (De Haan) in the brackish-water habitat (Kaifu et al. 2013). In the present study, no shrimp species was infected with nematode larvae, but we cannot here conclude whether it was caused by host specificity or sampling limitation; our collection only focused on the upper-intertidal zone. Since higher intensity of $H$. anguillae in Japanese eels has been found from a high-salinity area of the present cove (Katahira et al. 2011), further investigations in lower-intertidal or subtidal habitats are needed to detect preferred intermediate host species and/or individuals. Incidentally, no infection in 
freshwater decapods appears to agree with our assumption that $H$. anguillae is a halophilic parasite.

Of the two crab species infected with the nematode larvae, the species of the genus Hemigrapsus Dana is restrictedly identified in the present study because there are two closely related sibling species, i.e. $H$. penicillatus (De Haan) and $H$. takanoi Asakura et Watanabe, commonly distributed in intertidal zones of Japan and surrounding countries (see Asakura and Watanabe 2005, Asakura 2006, Asakura et al. 2008). Both congeners are usually hard to distinguish each other at individual level without genetic analyses, depending on sex, ontogenetic development and handling status of specimen (see Yamasaki et al. 2011). For the more strict investigations on the host utilisation in larvae of $H$. anguillae, therefore, comprehensive approach combining genetic analyses is needed. Considering the common occurrences of these varunid crabs along with the geographical distribution of Japanese eels as probable predators (see Asakura and Watanabe 2005, Asakura 2006), further investigations on the infection status of $H$. anguillae larvae in these crabs as intermediate hosts may provide qualitative and quantitative insights into detail feeding habits of the eels.

Acknowledgements. We are grateful to M. Sato and K. Kan, Department of Earth and Environmental Sciences, Faculty of Science, Kagoshima University, for providing useful information to start this survey. We also thank K. Mizuno, Ehime Prefectural Uwajima Fishery High School, for assistance the field survey, and $\mathrm{H}$. Kajihara and K. Kakui for permission to use the SEM facilities at the Division of Biological Science, Hokkaido University. K. Ogawa and T. Iwaki, Meguro Parasitological Museum, Tokyo, supported us to examine the type specimens. Part of this study was financially supported by Grants-in-Aid for JSPS Fellows (No. 254625 to H.K.) and for Scientific Research (C) (No. 24580267 to K.N.).

\section{REFERENCES}

Anderson R.C. 2000: Nematode Parasites of Vertebrates: Their Development and Transmission. CAB International, Wallingford, $650 \mathrm{pp}$.

Asakura A. 2006: The story behind the discovery of Hemigrapsus takanoi Asakura \& Watanabe, 2005, a cryptic species of crab, previously thought to be the common Japanese intertidal crab $H$. penicillatus (Decapoda: Brachyura: Grapsoidea). TAXA, Proc. Jpn. Soc. Syst. Zool. 21: 33-39. (In Japanese with English abstract.)

Asakura A., Mingkid W., Yamasaki I., Watanabe S. 2008 Revalidation of Hemigrapsus takanoi Asakura \& Watanabe, 2005: a rebuttal to "Sakai (2007): comments on an invalid nomial species, Hemigrapsus takanoi Asakura \& Watanabe, 2005, a synonym of Hemigrapsus penicillatus (DeHaan, 1835) (Decapoda, Brachyura, Grapsidae)." Crustaceana 81: 1263-1273.

Asakura A., Watanabe S. 2005: Hemigrapsus takanoi, new species, a sibling species of the common Japanese intertidal crab $H$. penicillatus (Decapoda: Brachyura: Grapsoidea). J. Crust. Biol. 25: 279-292.

Chabaud A.G. 2009: Spirurida. In: R.C. Anderson, A.G. Chabaud and S. Willmott (Eds.), Keys to the Nematode Parasites of Vertebrates. Archival Volume. CABI, Wallingford, pp. 334-360.

Chabaud A.G., Campana-Reuget Y. 1956: Le gentre Ortleppina Schulz 1927, parasite d'Apodes, et non de Serpents, est synonyme du genre Heliconema Travassos 1919. Ann. Parasitol. Hum. Comp. 31: 308-309.

Crites J.L., Overstreet R.M. 1991: Heliconema brooksi n. sp. (Nematoda: Physalopteridae) from the ophichthid eel Ophichthus gomesi in the Gulf of Mexico. J. Parasitol. 77: 42-50.

DE N.C. 1988: Remarks on the validity of the species Notopteroides alatae Majumdar, 1965. Folia Parasitol. 35: 281-284.

De N.C., Ghosh M., Majumdar G. 1978: Records of some little known nematodes from Indian fishes. Folia Parasitol. 25: 317-322.

Kaifu K., Miyazaki S., Aoyama J., Kimura S., Tsukamoto K. 2013: Diet of Japanese eels Anguilla japonica in the Kojima BayAsahi River system, Japan. Environ. Biol. Fish 96: 439-446.

Katahira H., Mizuno K., Nagasawa K. 2011: Host size- and habitat-dependent intensity of Heliconema longissimum (Nematoda: Physalopteridae) in the Japanese eel (Anguilla japonica). J. Parasitol. 97: 994-998.

Li L., LiU Y.Y., LiU B.C., Zhang L.P. 2013: Morphological and molecular characterisation of Heliconema hainanensis sp. nov. (Spirurina: Physalopteridae) from congers in the South China
Sea, with a key to the species of Heliconema. Mem. Inst. Oswaldo Cruz, Rio de Janeiro 108: 41-47.

Mizuno K., Nagasawa K. 2010: Occurrence and habitats of the giant mottled eel Anguilla marmorata (Anguilliformes, Anguillidae) in rivers of Ehime Prefecture, Japan. Biogeography 12: 133-139.

Moravec F. 1998: Nematodes of Freshwater Fishes of the Neotropical Region. Academia, Prague, 464 pp.

Moravec F. 2007: Some aspects of the taxonomy and biology of adult spirurine nematodes parasitic in fishes: a review. Folia Parasitol. 54: 239-257.

Moravec F. 2013: Parasitic Nematodes of Freshwater Fishes of Europe. Revised Second Edition. Academia, Prahue, 601 pp.

Moravec F., Amin A. 1978: Some helminth parasites, excluding Monogenea, from fishes of Afghanistan. Acta. Sci. Nat. Brno 12: $1-45$.

Moravec F., Santos M.D., Brasil-Sato M. 2008: Redescription of Cystidicoloides fischeri based on specimens from piranhas in Brazil, and erection of a new genus (Nematoda: Cystidicolidae). J. Parasitol. 94: 889-897.

Moravec F., Sheeba S., Kumar A.B. 2013a: Observations on nematodes from the Indonesian shortfin eel Anguilla bicolor bicolor McClelland in India, including a revalidation of Heliconema ahiri Karve, 1941 (Physalopteridae). Acta Parasitol. 58: 496-503.

Moravec F., Taraschewski H., Anantaphruti M.T., MaipanICH W., LeOPRASERT T. 2007: Heliconema longissimum (Ortlepp, 1923) (Nematoda: Physalopteridae) from Pisodonophis boro (Teleostei: Ophichthidae) in Thailand, with remarks on the taxonomy of the Proleptinae Schulz, 1927. Syst. Parasitol. 66: 73-80.

Moravec F., Taraschewski H., Weyl O.L.F. 2013b: Redescription of Heliconema africanum (Linstow, 1899) n. comb. (Nematoda: Physalopteridae), a nematode parasite of freshwater eels (Anguilla spp.) in South Africa. Syst. Parasitol. 85: 263-269.

Nagasawa K., Umino T., Mizuno K. 2007: A checklist of the parasites of eels (Anguilla spp.) (Anguilliformes: Anguillidae) in Japan (1915-2007). J. Grad. Sch. Biosp. Sci. 46: 91-121.

Ogden C.G. 1969: A revision of the genus Heliconema Travassos, 1919, Physalopteridae (Nematoda). J. Nat. Hist. 3: 423-431.

Ortlepp R.J. 1922: The nematode genus Physaloptera Rud. Proc. Zool. Soc. London 92: 999-1107.

Sood M.L. 1970: On Paraleptus komiyai n. sp. (Physalopteridae Leiper, 1908: Nematoda) from a fresh water fish, Mastacembelus armatus from Lucknow, India. Jpn. J. Parasitol. 19: 437-439. 
SuYEHiRo Y. 1957: [On the ecology of parasites of Japanese eels]. In: Y. Suyehiro, Y. Oshima and Y. Hiyama (Eds.), Suisangaku Shusei. Tokyo University Press, Tokyo, pp. 415-418. (In Japanese.)

Taraschewski H., Boomker J., Knopf K., Moravec F. 2005 : Anguillicola papernai (Nematoda: Anguillicolidae) and other helminths parasitizing the African longfin eel Anguilla mossambica. Dis. Aquat. Org. 63: 185-195.

WoRMS 2013: Decapoda. World Register of Marine Species, www. marinespecies.org/aphia.php? $\mathrm{p}=$ taxdetails\&id=1130, 2/2014
Yamaguti S. 1935: Studies on the helminth fauna of Japan. Part 9. I. Nematodes of fishes. Jpn. J. Zool. 6: 337-386.

Yamasaki I., Doi W., Mingkid W.M., Yokota M., StrüssMANn C.A., Watanabe S. 2011: Molecular-based method to distinguish the sibling species Hemigrapsus penicillatus and Hemigrapsus takanoi (Decapoda: Brachyura: Varunidae). J. Crust. Biol. 31: 577-581.

Cite this article as: Katahira H., Nagasawa K. 2015: Heliconema anguillae Yamaguti, 1935, a physalopterid nematode found in Japanese eels: taxonomic resurrection with a note on the third-stage larva from intertidal crabs in western Japan. Folia Parasitol. 62: 028. 